\title{
Users' Perception of the Hospital Information System in a Maternity Hospital in Lampung, Indonesia
}

\author{
Al Asyary $1^{*}$, Arief Kurniawan Nur Prasetyo², Tris Eryando1, Solvay Gerke 3
}

\begin{abstract}
${ }^{1}$ Faculty of Public Health, Universitas Indonesia, Depok, Indonesia, ${ }^{2}$ Sisfomedika Co. Ltd./Study Program of Medical Records and Health Information, Faculty of Health, Jenderal Achmad Yani University, Yogyakarta, Indonesia, ${ }^{3}$ Center for Development Research, University of Bonn, Bonn, Germany
\end{abstract}

\begin{abstract}
Hospital information systems (HIS) have been applied on a massive scale; however, user evaluation of their effectiveness, efficiency, and service quality improvements remain rare. This study aimed to describe the utility of information systems from the users' point of view by using the Technology Acceptance Model (TAM) in a maternity hospital in Lampung, Indonesia. The study provided an overview of the features of the information system and the workflow of the user through this information system. Screenshots were taken by using Camtasia Studio 2.0 Trial Version application software for one day (two shifts) in the outpatient service. The HIS generally supported the workflow, but not all application modules were fully applied. The obstacles appear to be at the registration unit/outpatient registration and queue dashboard, cashier unit, pharmacy unit, medicine storage/room, and poly unit/checking room. A TAM framework, which included perceived ease of use and perceived usefulness of the information system, revealed that the currently implemented HIS was not perceived as optimal. However, users are still optimistic and aware of the usefulness of the information system in supporting their jobs. Thus, leaders have committed to initiate the potential development of this information system in the inpatient polyclinic.
\end{abstract}

Keywords: Health informatics, hospital information systems, users' perception

\section{Introduction}

Generally, the development of information system in the health care service is focused on designing and applying information technology that is suitable for the health care sector. ${ }^{1,2}$ Therefore, the assumption is that information system implementation only looks at the way the system is designed and purchased in its developmental stage. ${ }^{3}$ It is very rare to pay attention to the level of acceptance by health care workers as end users during the development of an information system. Consequently, there are many cases of information system implementation failure because of users' resistance to use such information technology. Harmony between technology and healthcare workers' systems will bring about user acceptance of or resistance to the technology and determine whether they use it and integrate it into their

How to Cite: Asyary A, Prasetyo AKN, Eryando T, Gerke S. Users' perception of the hospital information systems in a maternity hospital in Lampung, Indonesia. Kesmas: National Public Health Journal. 2019; 14(2): 76-81. (doi: 10.21109/kesmas.v14i2.2574) routines.

In several studies, there are many exceptions, such as the framework for evaluating an information system in the health care service. However, in explaining and knowing the general reaction of the user toward the information system, the Technology Acceptance Model (TAM) is one commonly used model, comprising as much as $10 \%$ of all models evaluating information systems. ${ }^{4}$ A percentage of $30 \%-40 \%$ shows significant result toward the acceptance of user's technology, although it is still simple. ${ }^{5}$ In health care services, the TAM framework is considered to be too economical. It is because of the actualization of this simple concept has not been able to be developed yet in a more detailed and in-depth way as the thought framework in exploring user's acceptance as one of the important aspects in the

Correspondence*: Al Asyary, Faculty of Public Health, Universitas Indonesia, A Building 2nd Floor Kampus Baru UI Depok 16424, Indonesia, Phone/Fax: +6221-7863479, E-mail: al.asyary13@gmail.com

Received : October $24^{\text {th }} 2018$

Revised : January 24th 2019

Accepted : September $6^{\text {th }} 2019$ 
information system implementation business in health care service. 6,7

A maternity hospital in Lampung Province is currently applying the Computerized Provider Order Entry system as the clinical information system for supporting health care services in the outpatient polyclinic. In simple terms, the provider, in this case, the specialist physician, orders a prescription, a physician's assistant (nurse in the examination room/polyclinic) inputs the prescription into the system, the prescription is transmitted to other units, and the patient obtains the prescribed medication from the pharmacy unit. The outpatient information system consists of four units, that are registration, the practice room, the pharmacy and pharmacy storage, and the cashier. There are 20 end users, each of whom has direct access to or can deal with one or more units, for example, one end user can deal with the registration unit and the cashier unit. The outpatient service can be run in two shifts, shift I (07:00 a.m. - 02:30 p.m.) and shift II (02:30 p.m. - 09:00 p.m.). Therefore, the aim of this study was to describe information system utilization from the perspective of users by applying the TAM framework in the early phase of the implementation of a clinical information system at a maternity hospital in Lampung.

\section{Method}

A system analysis with action research was conducted to evaluate to what extent the information system was used, including which features were used and which were not used, in the line of duty. Furthermore, information system utilization perception of users was also measured by using the TAM framework, which focused on perceived of ease of use and perceived usefulness. The semistructured questionnaire of the TAM model framework was used to evaluate these two aspects. Perceived ease of use is determined by examining the degree to which someone believes that a technology can be used easily. Perceived usefulness measures the degree to which someone feels that a technology benefits their productivity. Furthermore, to assess problems that occur while using the features of the information system modules, whether it be in commonly used or rarely used modules, a screenshot should be taken by using the software application Camtasia Studio 2.0 Trial Version 30 days for one day (two shifts) of the outpatient service.

These features in the information system are emphasized by four criteria; that are the patient's sociodemographic data, including the patient's full name (given and family names), the patient's telephone number, the patient's full address, the patient's age, the patient's emergency contact or guardian, and the consent form; the patient's medical records; validation of the patient's medical records by medical personnel or other personnel involved in the patient's treatment, so that the informa-

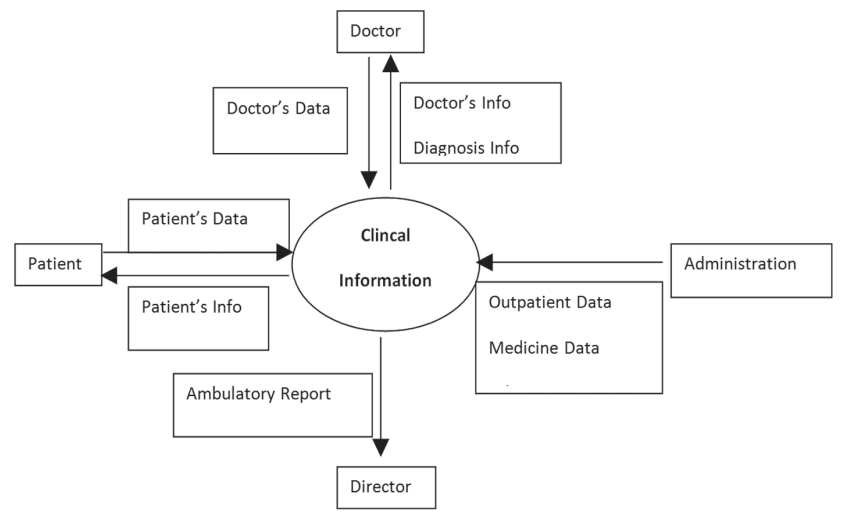

Figure 1. The Evaluation Framework of a Maternity Hospital in Lampung

tion can be accounted for legally; and admission procedures (administrative), including the date, time, filling in the fixated line also applying how to correcting the correct. ${ }^{8}$ Thus, from the workflow or the line of work, the types and frequencies of existing problems can be identified. This includes the temporal aspect, use of application features, inputted data visit, and outputted data visit (Figure 1).

This study collected and analyzed data using the framework to search for further structure of module features. Observations were conducted in stages to obtain an overview of the users' options when they worked with the hospital information system (HIS) module features. For example, when the user chooses/clicks on the "Registration" menu, three options of module features will appear, consisting of "Outpatient," "Inpatient," and "Emergency" modules. Each of these chosen/clicked menus would prompt the user to select one of several "module" features in this HIS. The sequence of the table is defined by which one of the menus and modules appeared first as the prompt click/choose.

This study continued to present additional modules according to each user's privileges. This indicated that only certain units could have access to these modules. For example, the cashier unit can only see the "Receipts Printing", "Outpatient Cashier", "Prescription Printing", "Inpatient Cashier," and "Income Report" module features on their HIS screen and do not have access to the inpatient nursing station unit. Users at the latter could only see nursing examination modules for work. The sequence numbers of these unit and privilege modules were defined by impromptu options that were chosen/clicked.

A letter of permission to conduct research at an maternity hospital in Lampung was from the Director of the Hospital. The data were confidential, and only the study investigators could access the data. This study also passed Ethics Review from the Concentration of Health Management and Information Systems, School of Public 
Health Sciences, Faculty of Medicine, Public Health and Nursing at Gadjah Mada University No. KE/FK/449/EC.

\section{Results}

Based on previous business applications, information system features on an maternity hospital in LampungIndonesia were composed of 12 types of modules, which are installed to eight types of user groups. The menu types are listed in Figure 2. Based on the workflow model, access rights are allocated to each user in the working units. Information system application model utilization in the outpatient clinic by the end user includes the outpatient registration unit, poly/practice room, cashier, and pharmacy/medicine storage. Therefore, the workflow can be described as follows (Figure 2).

The workflow starts in the registration unit, when the patient arrives and shows his or her medical treatment card. It can be retrieved through the search feature by

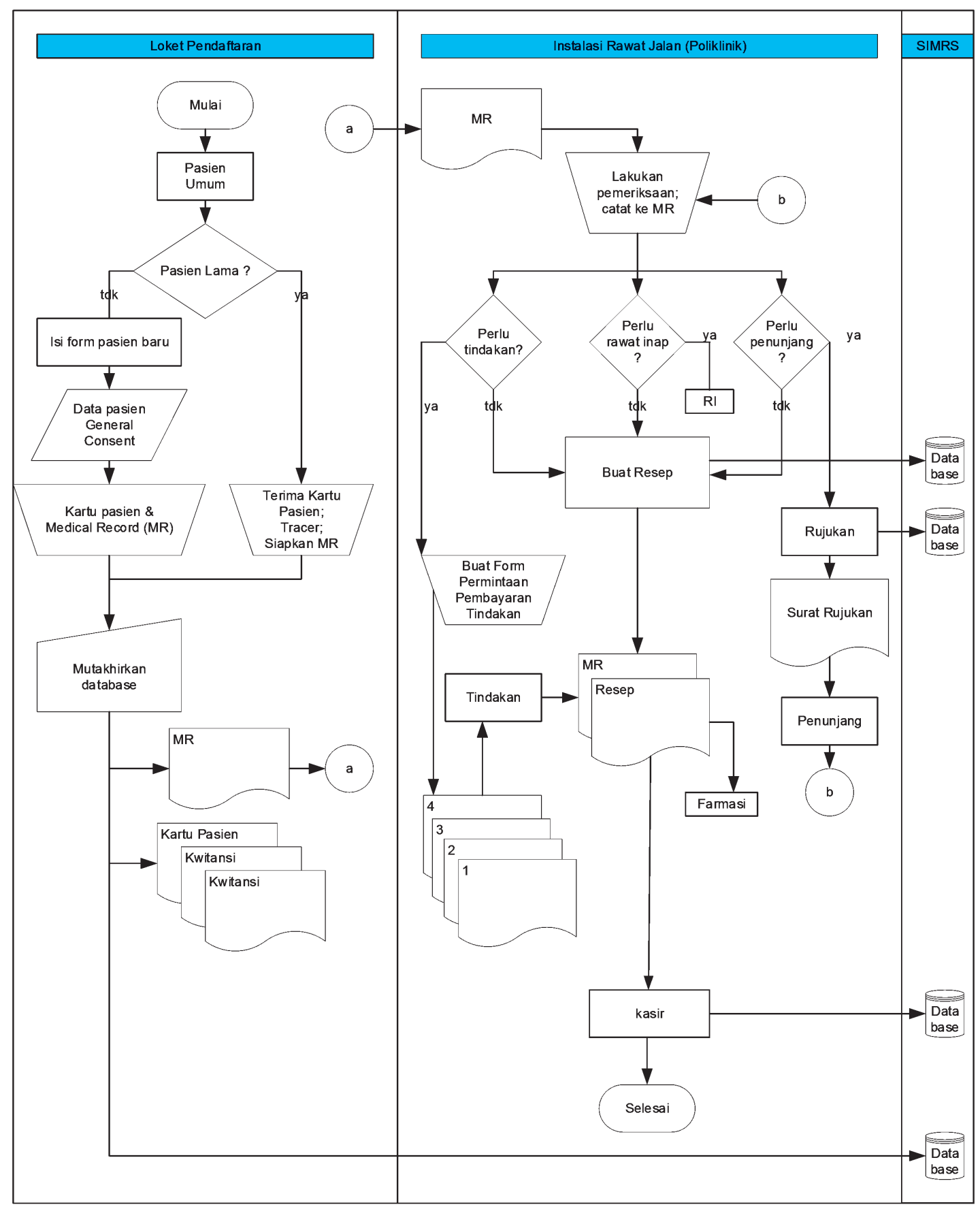

Figure 2. The Original Workflow of a Maternity Hospital in Lampung 
Table 1. Findings of the Hospital Information System Problem in a Maternity Hospital

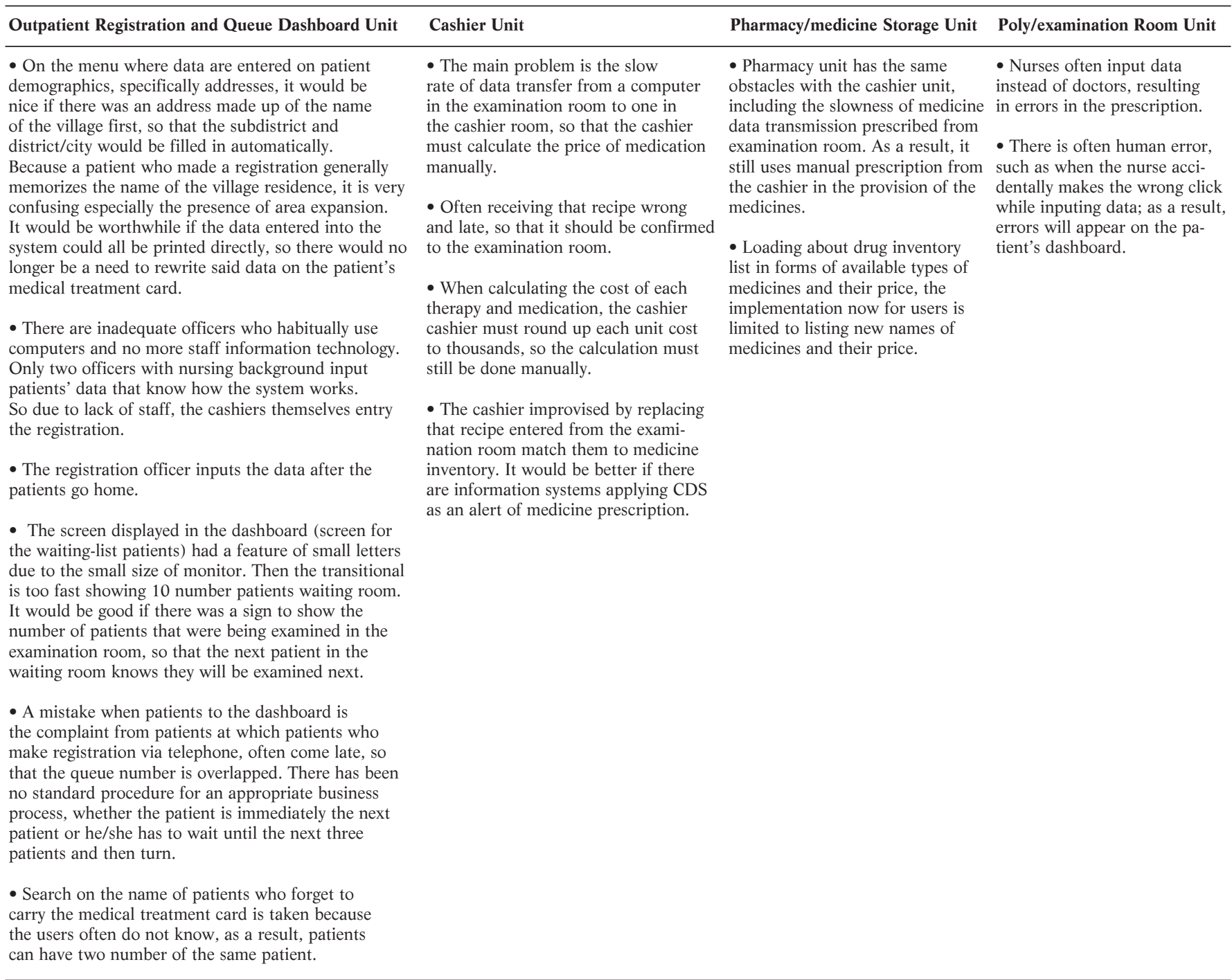

entering keywords (patient's number, patient's name, husband's name, etc.). Some problems regarding the application features in each unit in the outpatient polyclinic in a maternity hospital in Lampung can be described as follows (Table 1).

\section{Discussion}

Application model utilization was not as perfect as the one that has been composed to be applied in each unit. The application model provided to every outpatient service unit was not optimally used. One application model was not used once by the users, and the reason given was ignorance of the application model as an information system feature. In general that module had not yet once used, good on a cashier until in units of pharmacies/warehouse medicine, was the report. Therefore, no information was produced from the data input into infor- mation system that were running. In addition, to report module, print module can do that. Moreover, in each unit, a printer was provided, whose function it was to print data by using the module. The printers' seals had not yet been broken because they had never been used. On the other hand, suppose in registration unit, in hope that the officer had to put in the data once in the computer, and the data could be printed as health care card form if the patient was registering.

The unwillingness of unknowing users is strongly affected by the lack of competent staff, particularly the absence of any more it staff in addition to the lack of mentoring from a vendor at the time of initial implementation. ${ }^{9}$ The educational background of the officers was also a significant influence on habits regarding the use of computer technology. A previous study reported that among the officers with college-level education were 
officers who only graduated highschool. ${ }^{3}$

In addition, the HIS met many obstacles to implementation. ${ }^{10-12}$ All maternity hospital in Lampung units agreed that data transmission from one unit to the other was slow, so that the other unit, which is obstructed manually, finished the job. Suppose there was only a data transmission receipt and therapy that must be paid for by the patient from space check into cash. As a result, the cashier should count again manually based on the list price of a who taped to the counter by using a calculator. Not to mention, when prescription drugs prescribed for space check were unavailable in the hospital's drug inventory. Finally, the cashier asked the specialist doctor to replace the type of medicines that were prescribed. This kind of misconduct might be crucial, because the principle function of an information system is not to hinder but to support the work of health care services. ${ }^{13}$

A unit cashier is an indispensable unit in the outpatient service, ${ }^{14,15}$ including in an maternity hospital in Lampung. This is because the cashier has multiple function, such as to receive the invoice from the examination room, to review the contents of prescription drugs given and determine if there is drug inventory/pharmacies, to record the price, and to send a prescription to the pharmacy. ${ }^{16}$ At certain times, when there are no officers in the registration unit, the officers must perform double duty (so the end user has double rights), as a cash unit and as a registration unit. For this, the unit cashier is required to know equation the effects of the types of a drug that equal and that is in inventory pharmaceutical warehouses, in addition, to take care of registration patients. As a result of the risk of error prescription very vulnerable to, remember function cashier last as the decision makers that recipe sometimes not doing confirmation at the doctor a specialist in the unit of space check concerned with the drug prescribed in patients.

The provision of prescriptions by unit pharmacies, it can be said less regard again that recipe written or displayed system of the unit of space check and units cash. In addition to the slowness of the last data transmission system, especially the unit pharmacies as a unit end in the service outpatient waiting for transmission of the unit of practices and cashier units, in which a possible change in the prescription in cashier unit, finally has to wait longer. As a result, in the provision of prescription, pharmacies officers see enough prescription manual given by the cashier unit, and when the prescribed last until in the hands of patients, display data transmission the recipe from the new system appears. Thus, it only became a kind of comparison for a prescription manual given. In other words, the information system in the unit was actually ineffectual.

An error actually originally occurred in the unit poly/examination room, in which the prescription given by specialist physicians was not supported by drug inventory in pharmaceutical warehouses. Often, an assistant to the specialist physician (physicians commonly act as nurses) makes mistakes in inputting the therapy and medicines prescribed. Human error due to the lack of interface features that provide conformity application by medicine inventory is accused of being the root of existing problems in the polyclinic outpatient, ${ }^{17,18}$ including in this study setting. Hence, the application of conformity features in support of a work niche is important for flagging errors. ${ }^{19,20}$

The principal problem was that there were no interface features that cross-reference the prescribed medicine with the medicine inventory available in the outpatient polyclinic in this maternity hospital in Lampung. This problem occured in the examination room unit with the medicine storage unit. The main problem was the slow transition of prescribing, which was troublesome for the existing workflows.

\section{Conclusion}

The TAM framework revealed that the user's perception of the real benefit of the current information system cannot be felt optimally (perceived usefulness). Yet, the user is still optimistic and aware of the benefits of the information system in supporting a faster and more efficient workflow (perceived of ease of use). The firmness of the higher management commitment, so that the user will implement the current information system in outpatient polyclinic and started to develop the potential initiative of the information system development in the outpatient poly.

\section{Acknowledgment}

This study was funded by Sisfomedika Co. Ltd. project in the Health Management and Information System Concentration, Faculty of Medicine, Public Health and Nursing, Gadjah Mada University. We thank to various parties namely: Adiharsa Winahyu, MIT, MPH and all directors and staff of a maternity hospital in Lampung. We also thank contributors that are Mr. Anis Fuad, Dr. Lutfan Lazuardi, and Mr. Guardian Yoki Sanjaya.

\section{References}

1. Ologeanu-Taddei R, Morquin D, Domingo H, Bourret R. Understanding the acceptance factors of an hospital information system: evidence from a French University Hospital. AMIA. Annu Symp Proceedings AMIA Symp. 2015: 1001-7.

2. AIHW. Review and evaluation of Australian information about primary health care. Melbourne: AIHW; 2011. p. 256.

3. Asyary A, Kusnanto H, Fuad A. Sistem peresepan elektronik pada keselamatan pengobatan pasien. Kesmas: National Public Health Journal. 
2013; 8(3): 119-24.

4. Hwang JY, Kim KY, Lee KH. Factors that influence the acceptance of telemetry by emergency medical technicians in ambulances: an application of the extended technology acceptance model. Telemedicine Journal and e-Health. 2014; 20(12): 1127-34.

5. Garavand A, Mohseni M, Asadi H, Etemadi M, Moradi-Joo M, Moosavi A. Factors influencing the adoption of health information technologies: a systematic review. Electron Physician. 2016; 8(8): 2713-8.

6. Aggelidis VP, Chatzoglou PD. Using a modified technology acceptance model in hospitals. International Journal of Medical Informatics. 2009; 78(2): 115-26.

7. Gagnon MP, Orruno E, Asua J, Abdeljelil A Ben, Emparanza J. Using a modified technology acceptance model to evaluate healthcare professionals' adoption of a new telemonitoring system. Telemedicine Journal and e-Health. 2012; 18(1): 54-9.

8. Gemala RH. Pedoman pengelolaan rekam medis rumah sakit di Indonesia. Jakarta: Direktor Jendral Pelayanan Medik Departemen Keehatan Republik Indonesia; 2010.

9. Veruswati M, Asyary A. Implementation of information system toward health system strengthening in Indonesia: a policy brief. Public Health Indonesia. 2017; 3(3): 73-6.

10. Kilsdonk E, Peute LW, Jaspers MWM. Factors influencing implementation success of guideline-based clinical decision support systems: a systematic review and gaps analysis. International Journal of Medical Informatics. 2017; 98: 56-64.

11. Sligo J, Gauld R, Roberts V, Villa L. A literature review for large-scale health information system project planning, implementation and evaluation. International Journal of Medical Informatics. 2017; 97: 86-97.

12. Cresswell KM, Mozaffar H, Lee L, Williams R, Sheikh A. Workarounds to hospital electronic prescribing systems: a qualitative study in English hospitals. BMJ Quality \& Safety. 2017; 26(7): 542-51.

13. Handayani PW, Hidayanto AN, Pinem AA, Hapsari IC, Sandhyaduhita PI, Budi I. Acceptance model of a hospital information system. International Journal of Medical Informatics. 2017; 99: 11-28.

14. Michael GC, Aliyu I, Grema BA, Thacher TD. Impact of structural and interpersonal components of health care on user satisfaction with services of an outpatient clinic of a Nigerian tertiary hospital. Tropical Journal of Medical Research. 2017; 20(2): 139.

15. Lu C-C, Lin S-W, Chen H-J, Ying K-C. Optimal allocation of cashiers and pharmacists in large hospitals: a point-wise fluid-based dynamic queueing network approach. IEEE Access. 2017; 6: 2859-70.

16. Herman MJ, Handayani RS, Siahaan SA. Kajian praktik kefarmasian apoteker pada tatanan rumah sakit. Kesmas: National Public Health Journal. 2013; 7(8): 365-72.

17. Chana N, Porat T, Whittlesea C, Delaney B. Improving specialist drug prescribing in primary care using task and error analysis: an observational study. The British Journal of General Practice. 2017; 67(656): e15767.

18. Miller Jr DP, Latulipe C, Melius KA, Quandt SA, Arcury TA. Primary care providers' views of patient portals: interview study of perceived benefits and consequences. Journal of Medical Internet Research. 2016; 18(1): e8.

19. Jin Y, Yan M. Computer literacy and the construct validity of a high-stakes computer-based writing assessment. Language Assessment Quarterly. 2017; 14(2): 101-19.

20. Tsai HS, Shillair R, Cotten SR. Social support and "playing around" an examination of how older adults acquire digital literacy with tablet computers. Journal of Applied Gerontology. 2017; 36(1): 29-55. 